\title{
Electrical Drives for Crane Application
}

\author{
Nebojsa Mitrovic ${ }^{1}$, Milutin Petronijevic ${ }^{1}$, \\ Vojkan Kostic ${ }^{1}$ and Borislav Jeftenic ${ }^{2}$ \\ 1 University of Nis, Faculty of Electronic Engineering, \\ ${ }^{2}$ University of Belgrade, Faculty of Electrical Engineering, \\ Serbia
}

\section{Introduction}

A crane is the type of machine mainly used for handling heavy loads in different industry branches: metallurgy, paper and cement industry. By the construction, cranes are divided into the overhead and gantry cranes. An overhead crane, also known as a bridge crane, is a type of crane where the hook and line mechanism runs along a horizontal beam that itself travels on the two widely separated rails. Often it is in a factory building and runs along rails mounted on the two long walls. A gantry crane is similar to an overhead crane designed so that the bridge carrying the trolley is rigidly supported on two or more legs moving on fixed rails embedded in the floor. Stationary or mobile units can be installed outdoors or indoors. Some industries, for example port containers application or open storage bins, require wide span gantry cranes. In outdoor applications, the influence of the wind on the behavior of the drive may be considerable (Busschots, 1991). Wind and skew can significantly influence a safe operation of the crane. This will certainly dispose the type design of the crane (lattice or box type design) from a mechanical aspect as well as the selection, size and control of crane electrical drives.

Electrical technology for crane control has undergone a significant change during the last few decades. The shift from Ward Leonard system to DC drive technology and the advent of powerful Insulated Gate Bipolar Transistors (IGBTs) during the 1990s enabled the introduction of the AC drive (Backstrand, 1992; Paul et al., 2008). Conventional AC operated crane drives use slip ring induction motor whose rotor windings are connected to power resistance in 4 to 5 steps by power contactors. Reversing is done by changing the phase sequence of the stator supply through line contactors. Braking is achieved by plugging. The main disadvantage is that the actual speed depends on the load. An electronic control system has recently been added to continuously control rotor resistor value. Nowadays, these systems are replaced by frequency converters supplied squirrel-cage induction motors for all types of motion (Paul et al., 2008). Control concept based on application of Programmable Logic Controllers (PLC) and industrial communication networks (Fieldbuses) are a standard solution which is used in complex applications (Slutej et al.,1999).

An overhead and gantry cranes are typically used for moving containers, loading trucks or material storage. This crane type usually consists of three separate motions for transporting material. The first motion is the hoist, which raises and lowers the material. The second is 
the trolley (cross travel), which allows the hoist to be positioned directly above the material for placement. The third is the gantry or bridge motion (long travel), which allows the entire crane to be moved along the working area. Very often, in industrial applications additional drives as auxiliary hoist, power cable reel and conveyer belt are needed. Therefore, generally, a crane is complex machinery.

Depending on the crane capacity each of the mentioned drives, can be realized as multimotor. The term multi-motor drive is used to describe all the drives in a technological process. If the controlled operation of the drives is required by the process based on the controlled speed of the individual drives, the expression controlled multi-motor drives is adequate. For many of such drives, the mechanical coupling on the load side is typical (Jeftenic et al., 2006; Rockwell, 2000). In applications with cranes, coupling of the individual motors is realized by the mechanical transmition device, and it is usually technologically unbreakable.

\section{Possible load sharing configurations overview}

Controlled drives are usually fed from the power converter, which is also true for controlled multi-motor drives. The kind, the type and the number of converters used depend on the type of motors, their power ratings, and of the kind of the multi-motor drive. The control and regulation also depend on the type of the multi-motor drive, but also on the type of the converter selected, therefore the selection of the converter and the controller for these drives must be analyzed together. Regarding the power supply of the motor, the following cases are possible (Jeftenic et al., 2006):

- multiple motors fed by a single converter (multiple motors - single converter),

- motors controlled by separate converters (multiple motors - multiple converters).

In crane applications multi-motor drives are used very often and a proportional share of power between motors is required. Load sharing is a term used to describe a system where multiple converters and motors are coupled and used to run one mechanical load (Rockwell, 2000). In the strictest sense, load-sharing means that the amount of torque applied to the load from each motor is prescribed and carried out by each converter and motor set. Therefore, multiple motors and converters powering the same process must contribute its proportional share of power to the driven load.

Multiple motors that are run from a single converter do not load share because torque control of individual motors is not possible. The load distribution, in that case, is influenced only by the correct selection of the torque-speed mechanical characteristic. For the squirrelcage induction motors, there is no economical method for the adjustment of the mechanical characteristic of the ready-made motors, but this has to be done during the selection. For the slip-ring induction motor, the mechanical characteristic can be adjusted afterwards, with the inclusion of the rotor resistors. Motors that are controlled by separate converters without any interconnection also do not share the load. The lack of interconnection defeats any possible comparison and error signal generation that is required to compensate for the differences in the load that is applied to any single drive and motor set.

Control topologies for load sharing consider the presence of interconnection, i.e. information knowledge about load (motor current or torque). There are three categories of load sharing techniques: common speed reference, torque follower and speed trim follower. 
The common speed reference is the simplest the least precise and the less flexible form of load sharing to set up, Fig. 1a). The precision of this control depends on the drives control algorithm, the motor characteristics and the type of load to be controlled.

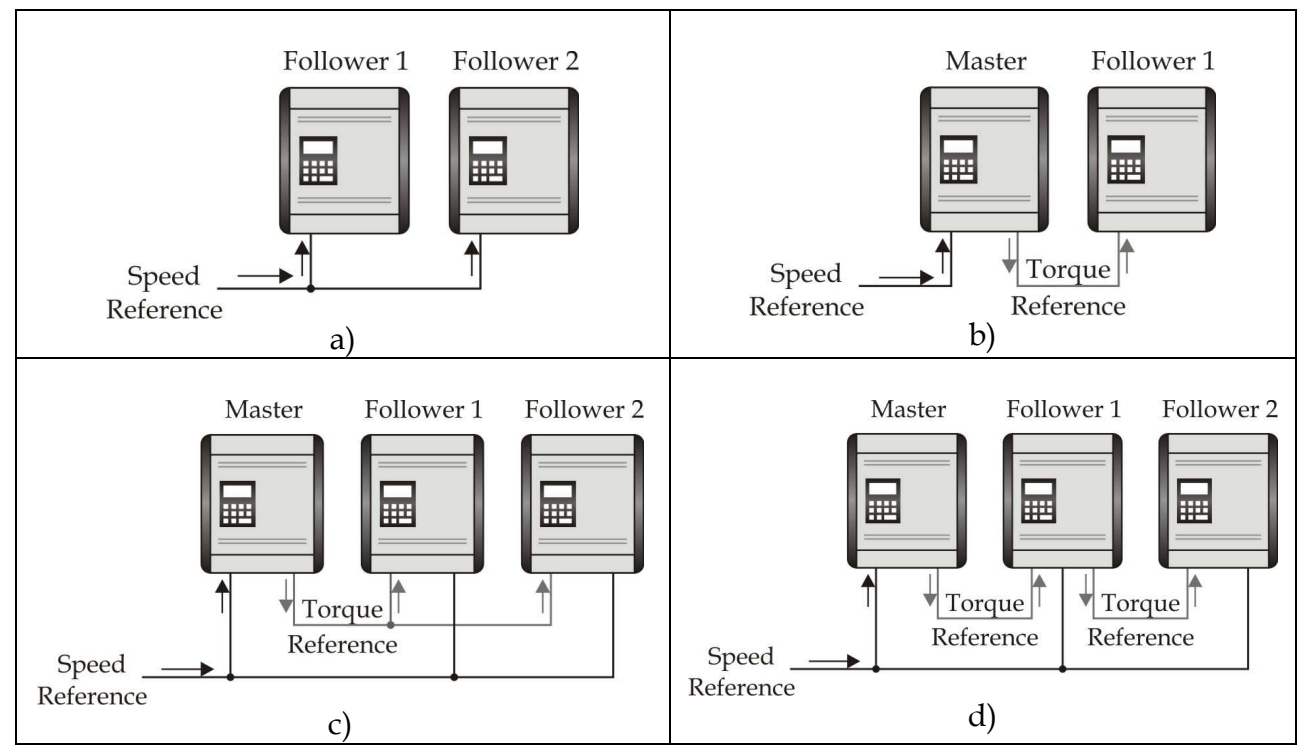

Fig. 1. Load sharing configuration a) Common speed reference, b) Torque follower, c) and d) Speed trim follower.

The torque follower type of load sharing requires the frequency converter to have the capability of operation in "torque mode", Fig. 1b). If speed regulation is required, one of the converters ("master") may be in "speed mode". In speed mode controller provides a torque command at output which can be distributed to the other converters ("slaves" or "torque followers"). The second converter operates in torque regulation mode with the torque reference of the master as command. This torque signal may be scaled to divide load sharing in any desired ratio.

In speed trim follower configuration, Fig. 1.c) and d), all converters are operated in speed regulation mode and receive the same speed reference. The torque reference of the master is sent to the follower converters. Each follower converter compares its own torque reference with that of the master, Fig. 1c). The output of the comparator is an error signal that trims the speed of the follower. Alternative configuration cascades the torque reference comparison, Fig. 1d). The first follower compares the master to its internal value. The second follower compares the foregoing follower to its internal value etc.

\subsection{Torque and power requirements for crane drives}

Speed control is an essential feature in crane drives. It is required for allowing soft starting and stopping of the travel motions for enabling its correct positioning of load. For the lifting drive the speed control in a wide speed range, from zero to nominal values, is required. 
Because of the precision when raising and lowering load, the possibility of working at a very low speed and hold a load in the standstill is required, without using the mechanical brakes.

The torque and power that have to be delivered by the drive may be obtained from the torque versus speed characteristic from the load (so-called mechanical characteristics) and the differential equation of motion, (Belmans et al., 1993; Mitrovic et al., 2011).

The differential equation of motion, describing the behavior of the drive is:

$$
J \frac{d \omega}{d t}=T_{e}-T_{l}
$$

where $T_{e}$ is the electromagnetic torque of the motor, $T_{l}$ is the torque of the load, $J$ is the inertia of the drive. If $T_{e}>T_{l}$, the system accelerates $(d \omega / d t>0)$, if $T_{l} / T_{e}<0$ it decelerates $(d \omega / d t>0)$. The stedy state operation is reached if $T_{l}=T_{e}$ and $\omega=$ const.

Multiplying equation (1) by the rotating speed $\omega$, yields the power:

$$
P_{e}=\omega T_{e}=\omega T_{l}+\omega J \frac{d \omega}{d t}=P_{m}+P_{d}
$$

This equation shows that the mechanical power $P_{e}=\omega T_{e}$, obtained after the electromechanical conversion in the motor, is equal to the power absorbed by the load $P_{m}=\omega T_{l}$ only when the speed does not change. Otherwise, the amount corresponding to change in kinetic energy must be added (if the speed increases) or subtracted (if the speed decreases):

$$
P_{d}=\frac{d E_{k i n}}{d t}=\omega \frac{J d \omega}{d t}
$$

In the following, the travel and hoist motion of the crane drives will be analyzed.

The mechanical characteristic is given in Fig.2a) for travel motion. Apart from the zone around zero, the torque is constant. The available torque is used for accelerating the system. For a travel in one direction, braking and reversing to full speed in other direction, the speed reference signal is given by top curve of Fig.2b). The torque reference signal is generated by converter (second curve), leading to the machine actual speed. Multiplying the actual and torque reference, yields the actual power (third curve). The peak power is found the end of the acceleration period. If wind forces are taken into consideration, the torque versus speed curve is shifted horizontally as shown in Fig.2c). The torque and speed reference remain the same, as well as the actual speed. However, the torque reference and the actual power differ, as shown on Fig.2d).

During acceleration, kinetic energy is stored in the system. To stop the crane, this energy must be absorbed by the drive. In the indoor situation, this energy is well known and only present for a short period of time. For outdoor applications, the wind forces may become very important. When travelling in the same direction as the wind, the wind drives the crane and a situation may occur, where a continuous electrical braking is required. The drive must be capable of handling this inverse power direction either by consuming the power in a resistor or preferably by feeding it back to the supply. 

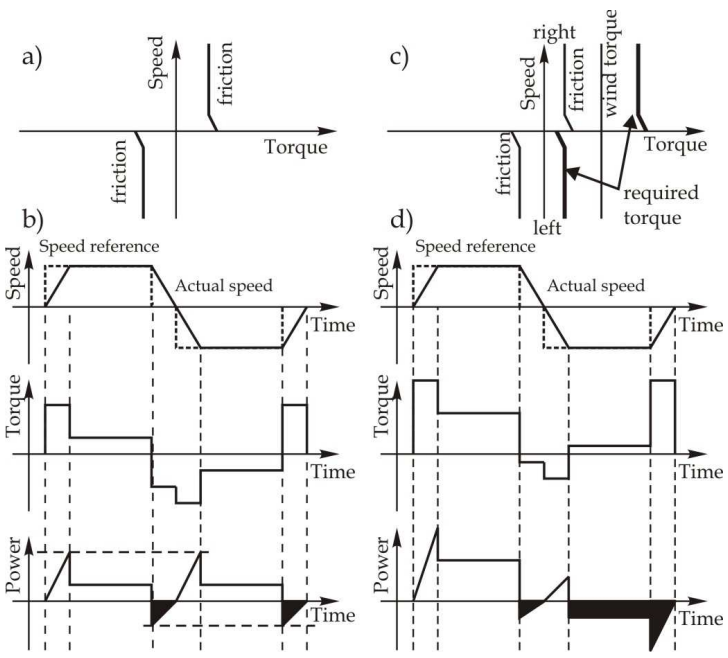

Fig. 2. Power and torque requirements for travel motion, a) and b) without wind influence, c) and d) with wind influence.
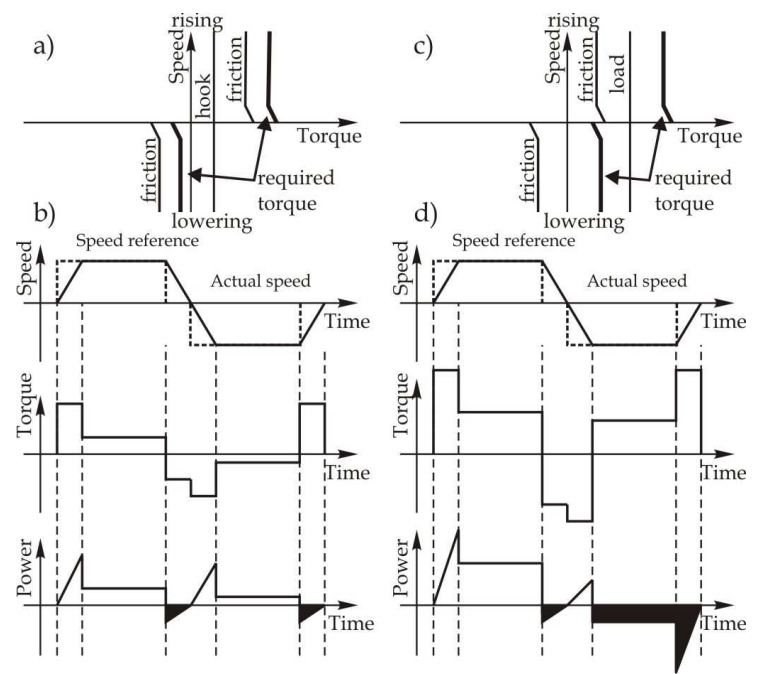

Fig. 3. Power and torque requirements for hoist a) and b) without load, c) and d) with load.

The hoist torque-speed characteristic is shown in Fig.3a) for an unloaded hook. The characteristic resembles the one for the travel motion. However, it is always asymmetric with respect to the vertical axis, due to the gravitation force. This asymmetry becomes more pronounced when the hook is loaded (Fig.3c). For both unloaded and loaded situation, the speed, torque and power are given in Fig.3b) and Fig.4d). Again the amount of braking power is indicated. The worst braking case with a hoist motion, is when sinking a loaded hook. It should be noted that the weight of the hook may be considerable. The hook may be simple, or may consist of several parts to handle the load. For the hoist motion, the speed 
control is very important in the low speed range: avoiding damage to the load when putting it down and minimizing the stress on the mechanical brakes.

\subsection{Frequency converters for induction motor drives}

Today's adjustable speed drives (ASD) in the low and mid power range are normally based on the concept of variable voltage, variable frequency (VVVF). Fig.4 shows the basic concept of a single variable speed drive. The three-phase AC supply network is rectified. The DC capacitor, which links the supply rectifier to the inverter, assures that the inverter sees a constant DC voltage from which it generates the required supply voltage and frequency to the motor.

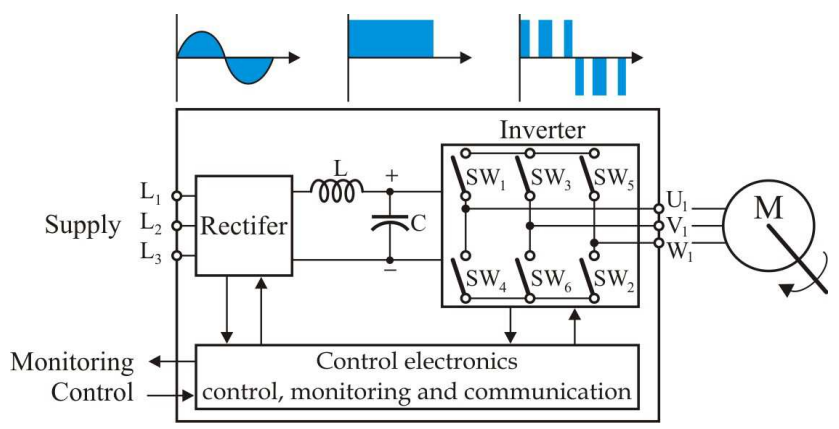

Fig. 4. Basic concept of a variable speed drive.

General classification divides induction motor control schemes into scalar and vector-based methods (Petronijevic et al., 2011). Opposite to scalar control, which allows control of only output voltage magnitude and frequency, the vector-based control methods enable control of instantaneous voltage, current and flux vectors. In numerous industrial applications, such as HVAC (heating, ventilation and air conditioning), fan or pump applications, good dynamic performances are not usually the main control objective. Fig. 5a) illustrates a V/Hz open loop control scheme, where pulse-width modulation (PWM) is realised applying the space vector technique (SVPWM) and output voltage fundamental component amplitude is modified with a voltage drop compensation $U_{s 0}$ at low output frequencies. Basic control structure of rotor field oriented control (RFO) is illustrated in Fig. 5b). Two inner PIcontrolled current loops for $d$ and $q$ stator current components are shown, as well as synchronous speed estimator ( $\omega_{\mathrm{e}}$, based on reference stator currents components). In its basic version, direct torque control (DTC) consists of a three-level hysteresis comparator for torque control and a two-level hysteresis comparator for flux control as shown in Fig.5.c).

Type of the front end converter, regardless of the control schemes, depends on the power and torque requirements of the drive. Adjustable speed drives in industrial applications are usually characterized by a power flow direction from the AC distribution system to the load (Rashid, 2001). This is, for example, the case of an ASD operating in the motoring mode. In this instance, the active power flows from the DC side to the AC side of the inverter. However, there are an important number of applications in which the motor begins to act as a generator and regenerates energy back into the DC bus of the drive. Moreover, this could be a transient condition as well a normal operating condition. This is known as the 
regenerative operating mode. For example, these regenerative conditions can occur when quickly decelerating a high inertia load and this can be considered as transient condition. The speed control of a load moving vertically downward (hoist) can be considered as normal operating condition.

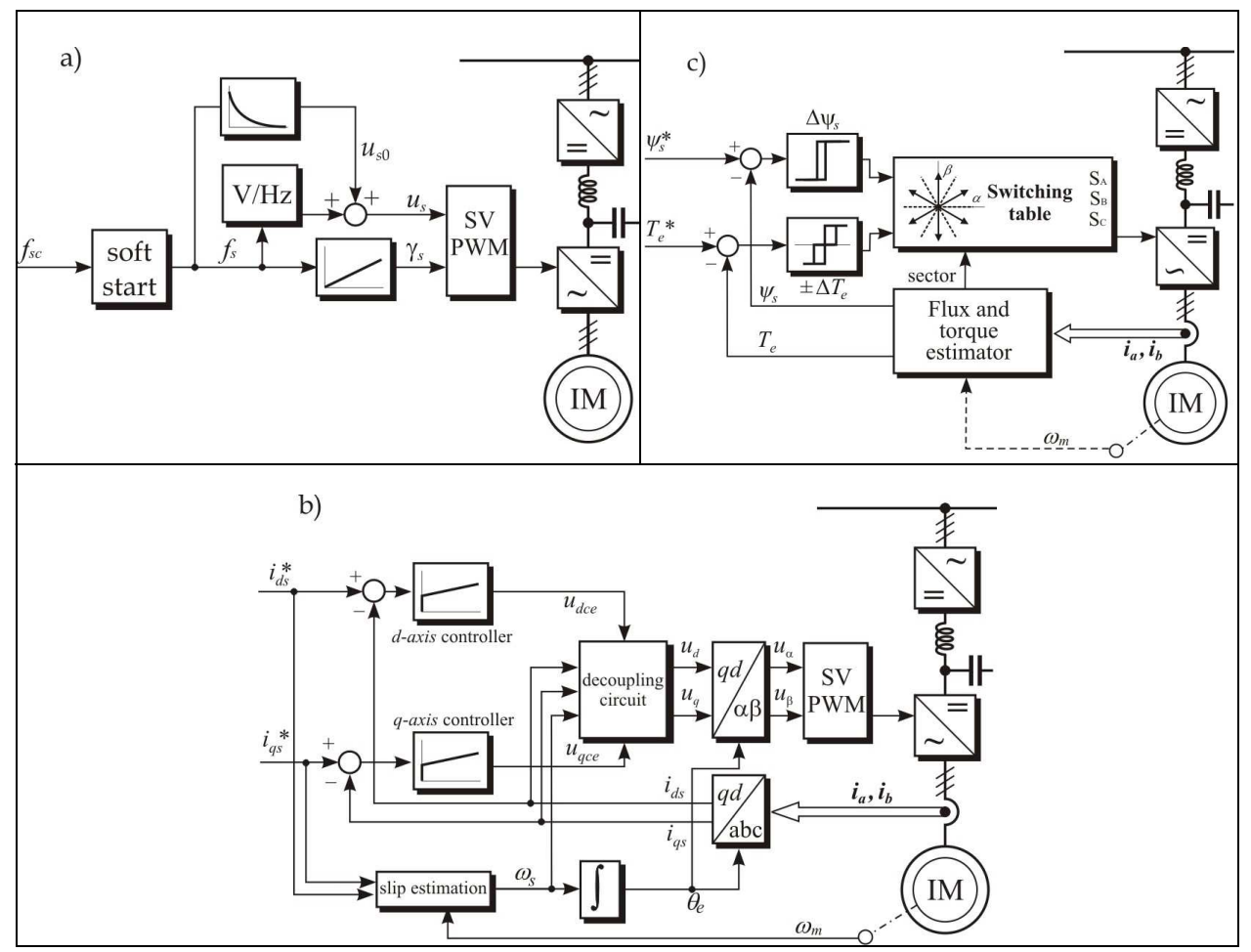

Fig. 5. Control scheme: a) V/Hz, b) vector control, c) DTC control.

Drive applications can be divided into three main categories according to speed and torque. The most common AC drive application is a single quadrant application where speed and torque always have the same direction, i.e. the power flow from inverter to process. The second category is two-quadrant applications where the direction of rotation remains unchanged but the direction of torque can change, i.e. the power flow may be from drive to motor or vice versa. The third category is fully four-quadrant applications where the direction of speed and torque can freely change. These applications are typically elevators, winches and cranes (ABB, 2011).

In order for an AC drive to operate in quadrant II or IV in speed-torque plane, a means must exist to deal with the electrical energy returned to the drive by the motor. The typical pulse width modulated AC drive is not designed for regenerating power back into the three phase supply lines. Electrical energy returned by the motor can cause voltage in the DC link to become excessively high when added to existing supply voltage. Various drive components can be damaged by this excessive voltage. These regenerative conditions can occur when: 
- quickly decelerating a high inertia load,

- controlling the speed of a load moving vertically downward (hoist, declining conveyor),

- a sudden drop in load torque occurs,

- the process requires repetitive acceleration and deceleration to a stop,

- controlling the speed of an unwind application.

In standard drives the rectifier is typically a 6-pulse diode rectifier only able to deliver power from the AC network to the DC bus but not vice versa. If the power flow changes as in two or four quadrant applications, the power fed by the process charges the DC capacitors and the DC bus voltage starts to rise. The capacitance is a relatively low value in an $\mathrm{AC}$ drive resulting in fast voltage rise, and the components of a frequency converter may only withstand voltage up to a certain specified level.

In order to prevent the DC bus voltage rising excessively, the inverter itself prevents the power flow from process to frequency converter. This is done by limiting the braking torque to keep a constant DC bus voltage level. This operation is called overvoltage control and it is a standard feature of most modern drives. However, this means that the braking profile of the machinery is not done according to the speed ramp specified by the user.

There are two technologies available to prevent the AC drive from reaching the trip level: Dynamic braking and active front end regeneration control. Each technology has its own advantages and disadvantages.

\section{Dynamic braking}

A dynamic brake consists of a chopper and a dynamic brake resistor. Fig. 6 shows a simplified dynamic braking schematic. The chopper is the dynamic braking circuitry that senses rising DC bus voltage and shunts the excess energy to the dynamic brake resistor. A chopper contains three significant power components: The chopper transistor is an IGBT. The chopper transistor is either ON or OFF, connecting the dynamic braking resistor to the $\mathrm{DC}$ bus and dissipating power, or isolating the resistor from the DC bus. The current rating of the chopper transistor determines the minimum resistance value used for the dynamic braking resistor. The chopper transistor voltage control regulates the voltage of the DC bus during regeneration. The dynamic braking resistor dissipates the regenerated energy in the form of heat.

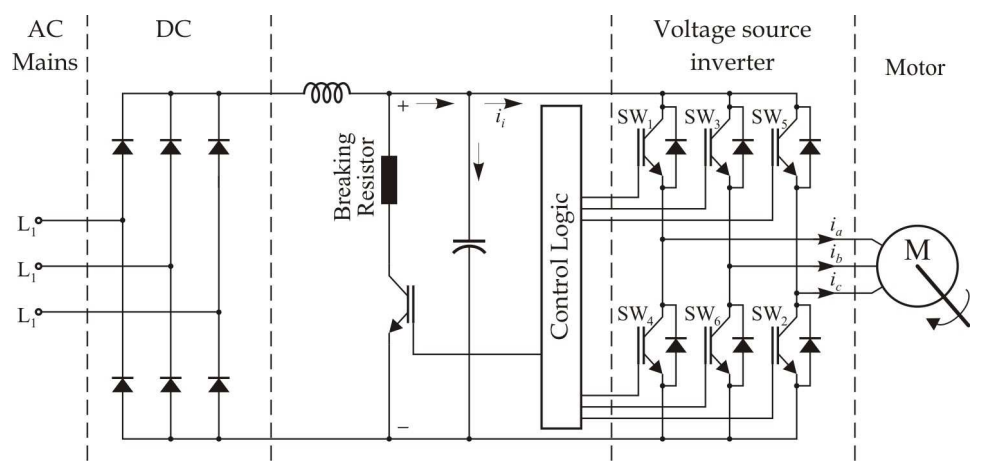

Fig. 6. Voltage source inverter with diode front end rectifier and dynamic brake module. 
As a general rule, dynamic braking can be used when the need to dissipate regenerative energy is on an occasional or periodic basis. In general, the motor power rating, speed, torque, and details regarding the regenerative mode of operation will be needed in order to estimate what dynamic braking resistor value is needed. The peak regenerative power of the drive must be calculated in order to determine the maximum resistance value of the dynamic braking resistor.

The peak breaking power required to decelerate the load, according to equation (4) is:

$$
P_{b}=\frac{J \omega_{b}\left(\omega_{b}-\omega_{0}\right)}{t_{b}}
$$

where $t_{b}$ represents total time of deceleration, $\omega_{b}$ and $\omega_{0}$ initial and final speed in the process of braking.

The value of $P_{b}$ can now be compared to the drive rating to determine if external braking module is needed. If peak braking power is $10 \%$ greater than rated drive power external braking module is recommended. Compare the peak braking power to that of the rated motor power, if the peak braking power is greater than 1.5 time that of the motor, then the deceleration time, needs to be increased so that the drive does not go into current limit.

The peak power dynamic brake resistance value can be calculated as:

$$
R_{d b}=\frac{V_{d c}^{2}}{P_{b}}
$$

The choice of the dynamic brake resistance value should be less than the value calculated by equation (5). If a dynamic braking resistance value greater than the ones imposed by the choice of the peak regenerative power is made and applied, the drive can trip off due to transient DC bus overvoltage problems. Once the approximate resistance value of the dynamic braking resistor is determined, the necessary power rating of the dynamic braking resistor can be calculated. The power rating of the dynamic braking resistor is estimated by applying what is known about the drive's motoring and regenerating modes of operation.

To calculate the average power dissipation the braking duty cycle must be determined. The percentage of time during an operating cycle $\left(t_{c}\right)$ when braking occurs $\left(t_{b}\right)$ is duty cycle $\left(\varepsilon=t_{b} / t_{c}\right)$. Assuming the deceleration rate is linear, average power is calculated as follows:

$$
P_{a v}=\frac{t_{b}}{t_{c}} \frac{P_{b}}{2} \frac{\omega_{b}+\omega_{0}}{\omega_{b}}
$$

Steady state power dissipation capacity of dynamic brake resistors must be greater than that average. If the dynamic braking resistor has a large thermodynamic heat capacity, then the resistor element will be able to absorb a large amount of energy without the temperature of the resistor element exceeding the operational temperature rating.

Fig.7a) shows the experimental results (DC voltage and chopper current) for the variable frequency drive with braking module in DC link and external braking resistor, under a step 
change of induction motor load in regenerative regime. Danfoss frequency (series VLT 5000) converter is used in experimental set-up. For the supply voltage of $400 \mathrm{~V}$, DC link voltage is about $540 \mathrm{~V}$. When negative load torque is applied, DC link voltage rises. The chopper transistor voltage control regulates the voltage of the DC bus during regeneration to near $800 \mathrm{~V}$ allowing current flow in the resistor. Regenerative energy is then realised into heat. After the end of the regenerative period, DC voltage returns to a value that corresponds to a motor regime. The Fig.7b) shows the line voltage and current at the input of the diode rectifier.

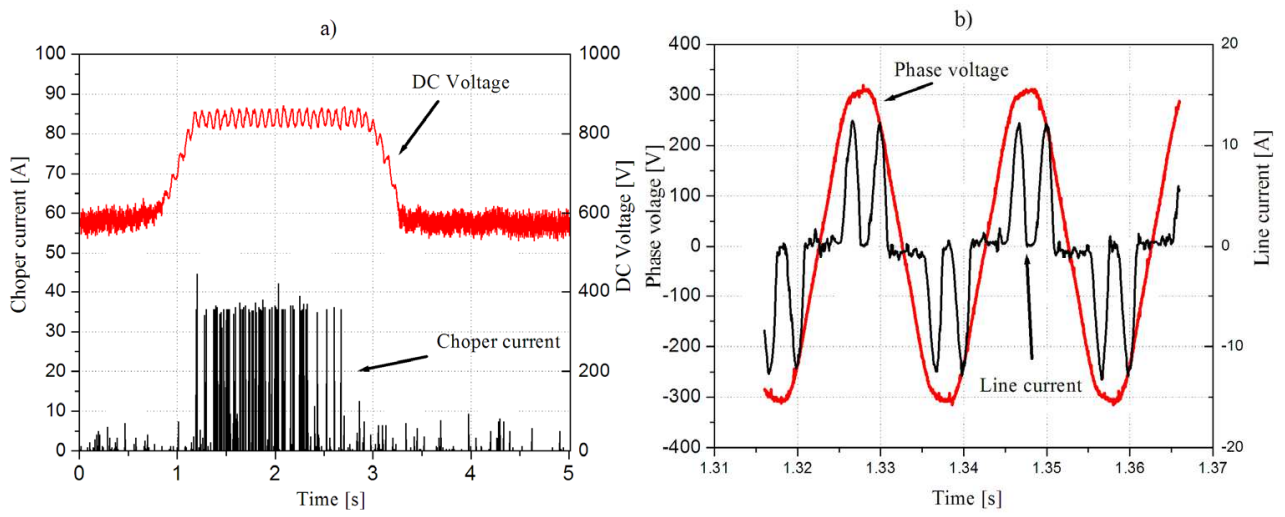

Fig. 7. a) DC voltage and chopper current, b) line voltage and current.

A voltage source PWM inverter with diode front-end rectifier is one of the most common power configurations used in modem variable speed AC drives, (Fig. 6). An uncontrolled diode rectifier has the advantage of being simple, robust, and low cost. However, it allows only unidirectional power flow. Therefore, energy returned from the motor must be dissipated on a power resistor controlled by a chopper connected across the dc link. A further restriction is that the maximum motor output voltage is always less than the supply voltage.

\section{Active front end rectifier}

Various alternative circuits can be used to recover the load energy and return it to power supply. One such scheme is shown in Fig. 8 and presents the most popular topology used in ASD. The diode rectifier is replaced with PWM voltage source rectifier. This is already an industrially implemented technology and known as most successful active front end (AFE) solution in ASD if regenerative operation is needed (e.g. for lowering the load in crane) and therefore was chosen by most global companies: Siemens, ABB, and others.

The term Active Front End Inverter refers to the power converter system consisting of the line-side converter with active switches such as IGBTs, the DC link capacitor bank, and the load-side inverter. The line-side converter normally functions as a rectifier. But, during regeneration it can also be operated as an inverter, feeding power back to the line. The lineside converter is popularly referred to as a PWM rectifier in the literature. This is due to the fact that, with active switches, the rectifier can be switched using a suitable pulse width modulation technique. 
The PWM rectifier basically operates as a boost chopper with AC voltage at the input, but DC voltage at the output. The intermediate DC-link voltage should be higher than the peak of the supply voltage. The required DC-link voltage needs be maintained constant during rectifier as well as inverter operation of the line side converter. The ripple in DC link voltage can be reduced using an appropriately sized capacitor bank. The AFE inverter topology for a motor drive application, as shown in Fig.8, has two three-phase, two-level PWM converters, one on the line side, and another on the load side. The configuration uses 12 controllable switches. The line-side converter is connected to the utility through inductor. The inductor is needed for boost operation of the line-side converter.

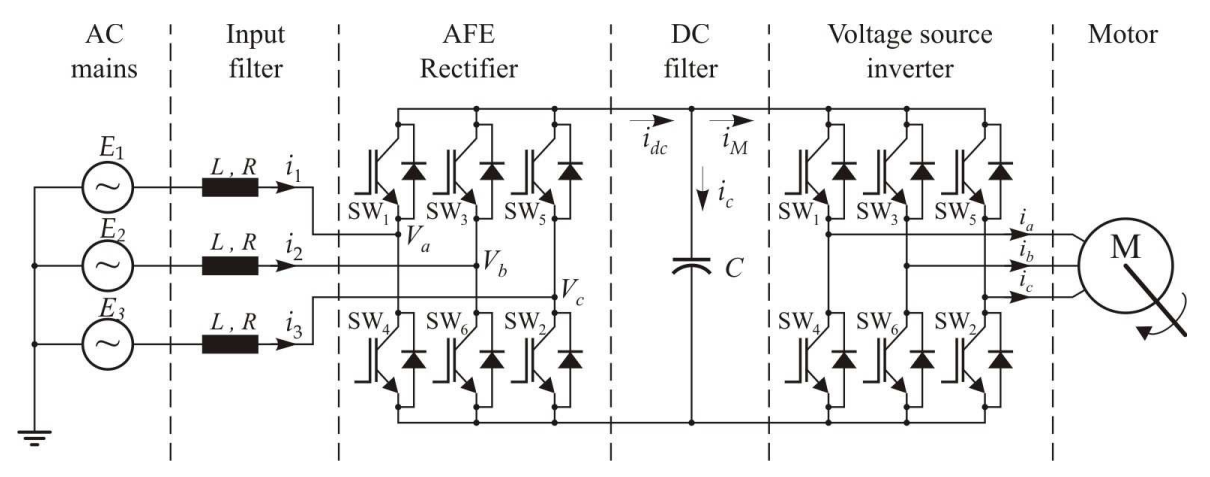

Fig. 8. Active front end inverter topology.

For a constant dc-link voltage, the IGBTs in the line-side converter are switched to produce three-phase PWM voltages at $a, b$, and $c$ input terminals. The line-side PWM voltages, generated in this way, control the line currents to the desired value. When DC link voltage drops below the reference value, the feed-back diodes carry the capacitor charging currents, and bring the DC-link voltage back to reference value.

The steady state characteristics as well as differential equations describing the dynamics of the front-end rectifier can be obtained independent of an inverter and motor load. This is because the DC-link voltage can be viewed as a voltage source, if $V_{d c}$ is maintained constant for the full operating range. The inverter is thus connected to the voltage source, whose terminal voltage $V_{d c}$, remains unaffected by any normal inverter and motor operation (Jiuhe et al., 2006).

Furthermore, as shown in Fig.8, the rectifier can also be viewed as connected to the voltage source $V_{d c}$. Thus, the rectifier is able to control magnitude and phase of PWM voltages $V_{a b c}$ irrespective of line voltages $E_{123}$.

The dynamic equations for each phase can be written as,

$$
\left[\begin{array}{l}
E_{1} \\
E_{2} \\
E_{3}
\end{array}\right]=L \frac{d}{d t}\left[\begin{array}{l}
i_{1} \\
i_{2} \\
i_{3}
\end{array}\right]+R\left[\begin{array}{l}
i_{1} \\
i_{2} \\
i_{3}
\end{array}\right]+\left[\begin{array}{c}
V_{a 0} \\
V_{b 0} \\
V_{c 0}
\end{array}\right]
$$

In synchronous rotating $d-q$ reference frame Equations 8 and 9 represent the dynamic $d-q$ model of an active front end inverter in a reference frame rotating at an angular speed of $\omega$. 


$$
\begin{aligned}
& L \frac{d i_{q e}}{d t}=E_{q e}-\omega L i_{d e}-R i_{q e}-V_{q e} \\
& L \frac{d i_{d e}}{d t}=E_{d e}+\omega L i_{q e}-R i_{d e}-V_{d e}
\end{aligned}
$$

The differential equation governing DC link voltage also needs to be added to the above set of system equations to completely define system dynamics:

$$
C \frac{d V_{d c}}{d t}=i_{d c}-i_{M}
$$

where, $i_{d c}$ is the total DC link current supplied by the rectifier, while $i_{M}$ is the load-side DC current which is the result of induction motor operation.

In Equations 8 and 9, the terms $E_{q e}$ and $E_{d e}$ are computed from source voltages, $E_{1}, E_{2}$, and $E_{3}$. Since line voltages are known, the angular frequency $\omega$, can be easily estimated. The PWM voltages $V_{q e}$ and $V_{d e}$ are the two inputs to the system which are generated using the sinetriangle PWM controller. $L$ and $R$ represent series impedance.

Equations (8 and 9) shows that $d-q$ current is related with both coupling voltages $\omega L i_{q}$ and $\omega L i_{d}$, and main voltage $E_{d}$ nd $E_{q}$, besides the influence of PWM voltage $V_{q e}$ and $V_{d e}$. Voltage $V_{q e}$ and $V_{d e}$ are the inputs, controlled in such a way as to generate desired currents. Now define new variables $V_{q e}^{\prime}$ and $V^{\prime}{ }_{d e}$ such that (Hartani \& Miloud, 2010):

$$
\begin{aligned}
& V_{q e}=-V_{q e}^{\prime}-\omega L i_{q e}+E_{q e} \\
& V_{d e}=-V_{d e}^{\prime}+\omega L i_{d e}+E_{d e}
\end{aligned}
$$

So that the new system dynamic equations become:

$$
\begin{aligned}
& L \frac{d i_{q e}}{d t}=-i_{q e} R+V_{q e}^{\prime} \\
& L \frac{d i_{s e}}{d t}=-i_{d e} R+V_{d e}^{\prime}
\end{aligned}
$$

We can see from equations that the two axis current are totally decoupled because $V_{q e}^{\prime}$ and $V^{\prime}{ }_{d e}$ are only related with $i_{q e}$ and $i_{d e}$ respectively.

The simple proportional-integral (PI) controllers are adopted in the current and voltage regulation, Fig.9. The control scheme of the PWM rectifier is based on a standard cascaded two-loop control scheme implemented in a $d-q$ rotating frame: a fast control loop to control the current in the boost inductors and a much slower control loop to maintain constant dclink voltage. The reference angle for the synchronous rotating $d-q$ frame $\theta$, is calculated, based on the three input phase voltages.

For the current control loop $d-q$ synchronously rotating reference frame with the fundamental supply voltage frequency is used (Odavic et al., 2005). The line currents $\left(i_{1}, i_{2}\right.$, $i_{3}$ ) are measured and transformed to the $d-q$ reference frame, Fig.10. 


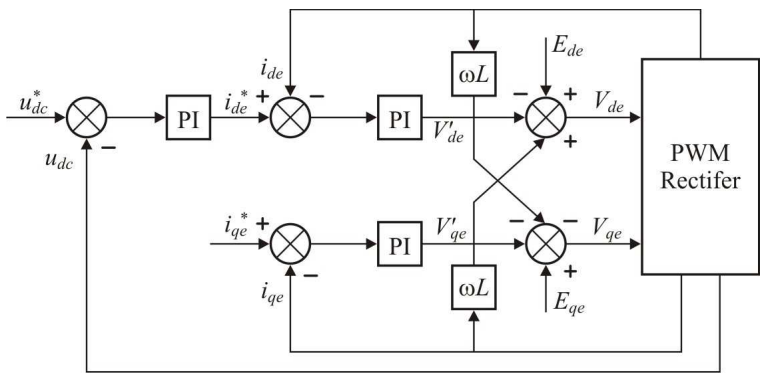

Fig. 9. Decoupled current control of PWM rectifier.

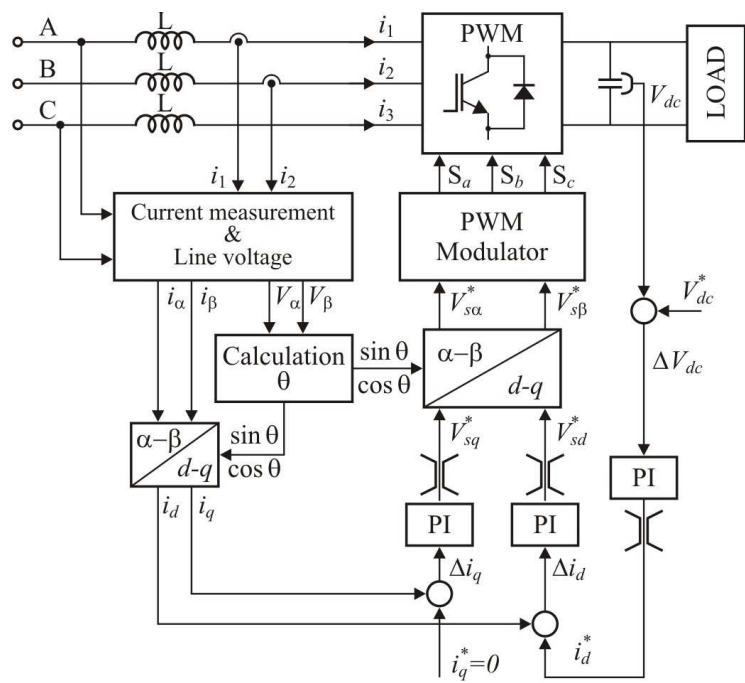

Fig. 10. Simplified block diagram of the AFE.

To get information about the position of the line voltage vector PLL (phase locked loop) is implemented. PI controllers for the $d-q$ components of line current are identical and $\omega L$ terms are included to eliminate the coupling effect among the $d$ and $q$ components. Outputs of the line current PI controllers present $d$ and $q$ components of the voltage across the line inductance. Subtracting this voltage from the supply voltage gives the converter voltage from the $\mathrm{AC}$ side that is used to get the modulation signal for proper switching of six switching devices.

The main task of the sinusoidal front end is to operate with the sinusoidal line current; so $d$ and $q$ components of the line current reference are DC values. Using this approach of control it is possible to control the output voltage of converter as well as the power factor of converter in the same time. To achieve unity power factor the reference of $q$ current component need to be set on zero.

Based on analysis, the simulation model of the whole is built using Matlab/Simulink to test the performance of the active front end rectifier. On the load side is the field oriented induction motor drive with topology as shown in Fig.5c). The whole system behavior is 
simulated as a discrete control system. The AC source is an ideal balanced three phase voltage source with frequency $50 \mathrm{~Hz}$. The phase to phase voltage is $400 \mathrm{~V}$. capacitor in DC link is $4700 \mu \mathrm{F}$. The line resistor and line inductance of each phase is $0.1 \Omega$ and $3 \mathrm{mH}$ respectively. The induction motor rated power is $30 \mathrm{~kW}$.

The induction machine is initially running at a constant speed reference (100 rad/s) and under a no load regime. From this situation, we apply a rated load torque during a time interval of $0.5 \mathrm{~s}$ and then we remove the load. This case corresponds to a step up and a step down torque perturbation.

The following figures summarize the results of the simulation. Fig. 11 and Fig.12 shows the behavior of the rectifier under a step change of the induction motor load. Fig.11 refers to the motor mode of operation (lifting) and Fig.2 to the generator mode (lowering).
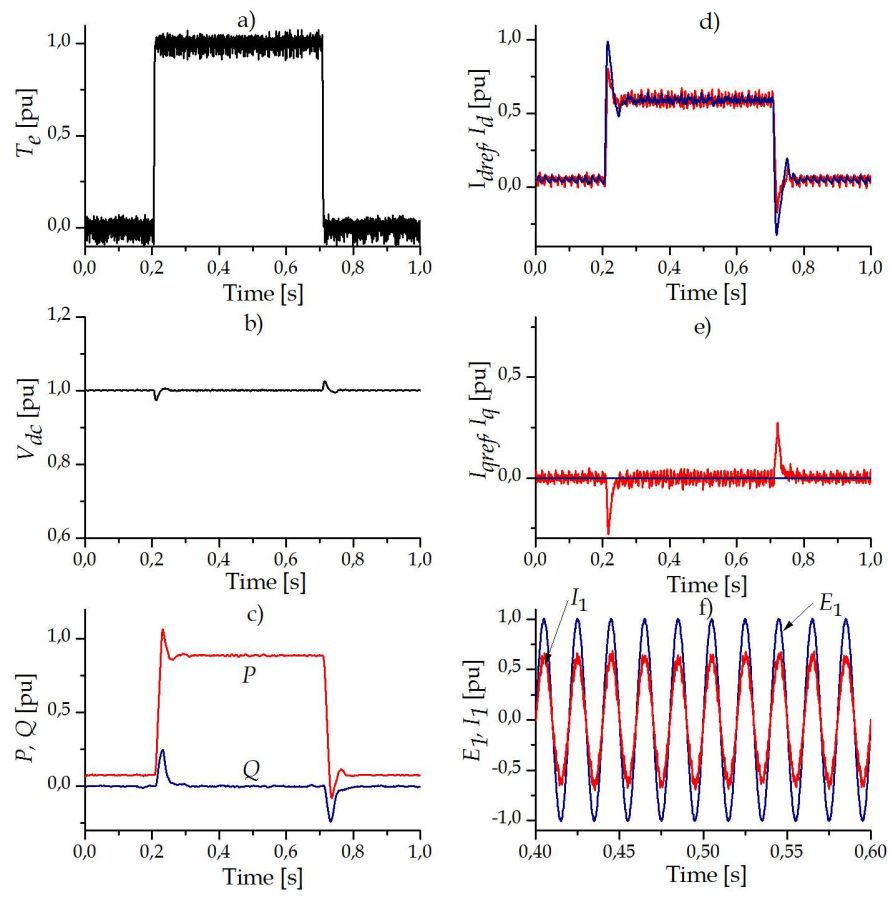

Fig. 11. Behavior of the rectifier under a step change of the induction motor load (motor operation).

Fig. 11b) and Fig. 12b) show the behavior of the DC link voltage of the PWM rectifier in response to a step change in the load. Fig. 11c) and Fig. 12c) presents the active and reactive power on the line side of converter. Since that the q component of the set point current is $I_{\text {qref }}=0$ (Fig.11e and Fig.12e) there is only $d$ current component (Fig.11d and Fig.12d), reactive power is zero. Fig.11f) and Fig.12f) show the behavior of steady state voltage and current delivered by the source when the line side converter works in the rectifier and regenerative mode. The input current is highly sinusoidal and keeps in phase with the voltage, reaching a unity power factor. 
The simulation results show that the rectifier has excellent dynamic behavior and following advantages:

- Power flow between the motor and the mains supply is possible in both directions, and so this makes the drive more efficient than when a braking resistor is used. As well as recovering energy during deceleration, it is possible to recover energy from overhauling load such as a crane when the load is being lowered.

- Good quality input current waveforms are possible with unity power factor.

- It is possible to boost the DC link voltage to a level that is higher than would be possible with a simple diode rectifier.
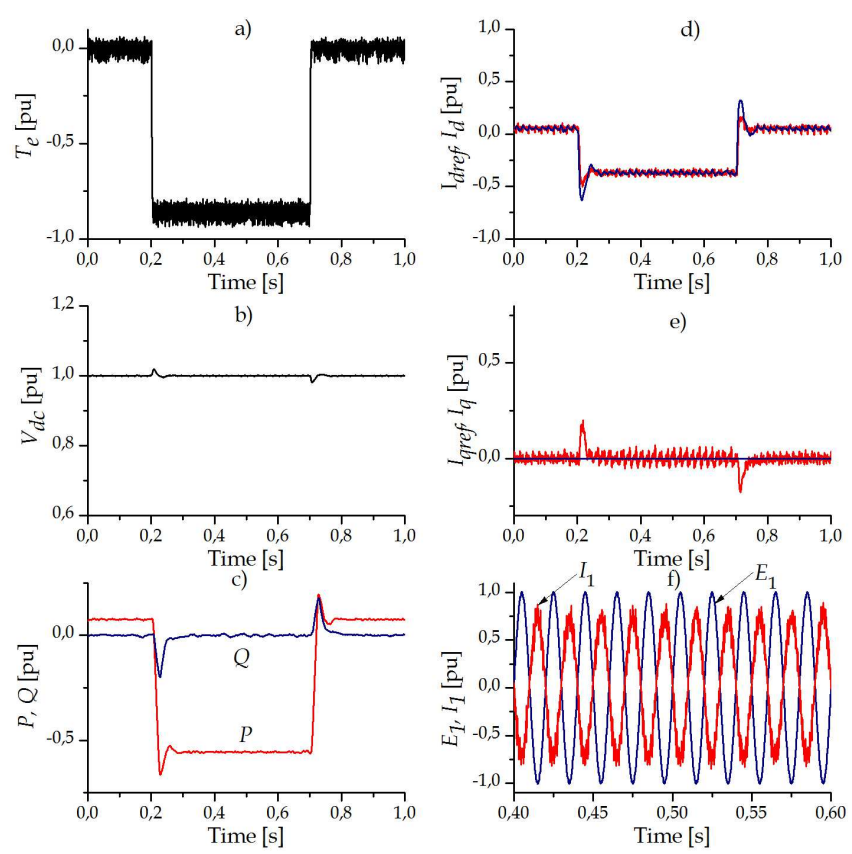

Fig. 12. Behavior of the rectifier under a step change of the induction motor load (generator operation).

\section{Case study 1: Derrick crane}

The experimental behavior analysis of some drives is considered in a derrick crane, which serves for load handling in many industry branches. The main task in adjustable speed drives design is a safe, multi-axis movement that allows material handling throughout the working area. The derrick crane with following technical details has been taken for experimentation with adjustable frequency drive:

- Main hoist load capacity: $60 \mathrm{t}$;

- Auxiliary load capacity: $12.5 \mathrm{t}$;

- Main hoist height: $46 \mathrm{~m}$;

- Auxiliary hoist height: $49 \mathrm{~m}$; 
- Jib boom radius: $0-82.5^{\circ}$;

- Length of runway rail path: $350 \mathrm{~m}$

- Working conditions: outdoor.

Using AFE rectifier/regenerative unit on common DC bus, six groups of inverter-motor combinations are supplied:

- hoist motion with $2 \times 55 \mathrm{~kW}$ vector control inverter, the motor is a six pole, $2 \times 45 \mathrm{~kW}$,

- auxiliary hoist motion with a $55 \mathrm{~kW}$ vector control inverter, supplying a four pole, 45 $\mathrm{kW}$ motor,

- jib motion with $2 \times 55 \mathrm{~kW}$ vector control inverter, the motor is a six pole, $2 \times 45 \mathrm{~kW}$,

- travel motion with $3 \times 7.5 \mathrm{~kW}$ vector control inverter, the motor is six pole, $3 \times 7.5 \mathrm{~kW}$,

- motor driven cable reel with $3 \mathrm{~kW}$ vector control inverter supplying $3 \mathrm{~kW}$ motor,

- $\quad$ auxiliary drives with $8 \times 1.1 \mathrm{~kW}$ and motors $(8 \times 1.1 \mathrm{~kW})$.

The rating of the AFE rectifier/regenerative unit output at $\cos \varphi=1$ and $400 \mathrm{~V}$ supply voltage is $177 \mathrm{~kW}$. This is far less than the sum of the ratings of the individual invertors, being $300 \mathrm{~kW}$. In the Fig.13 crane with indicated drives is shown.

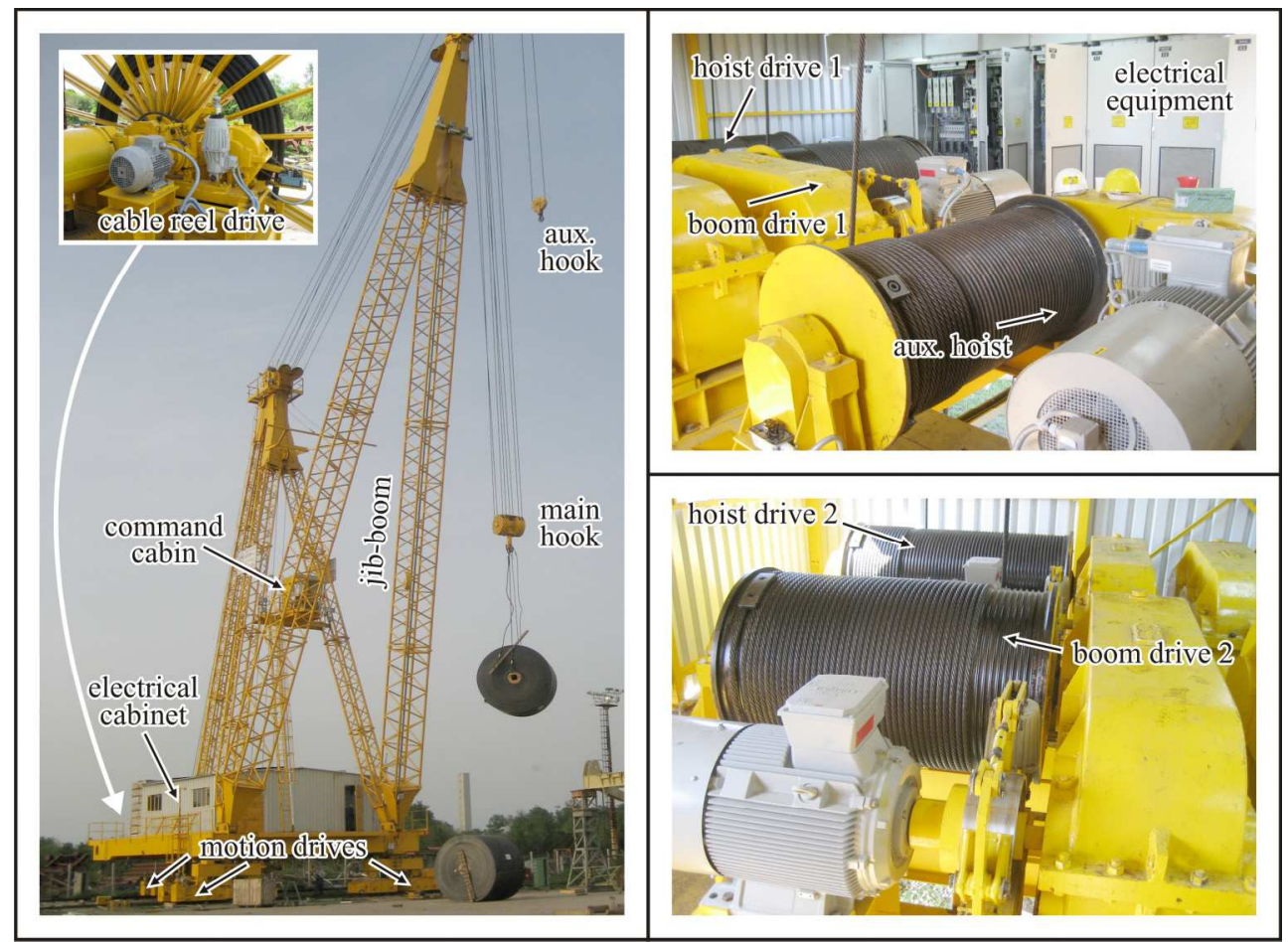

Fig. 13. Derrick crane with indicated drives.

Fig. 14 shows the power circuit topology of the derrick crane using AFEs at the input side. The AFE is connected upstream to the standard frequency inverter and consists of three components: 
- $\quad$ Active Infeed Converter.

- $\quad$ Line Filter Module (EMC filter, line contactor and charging circuit).

- $\quad$ Line Filter Choke

Power flows from the line through the input transformer and the input reactance into AFE, creating a common DC bus. The inverters take energy from the common DC bus to control the induction motors for the different movements.

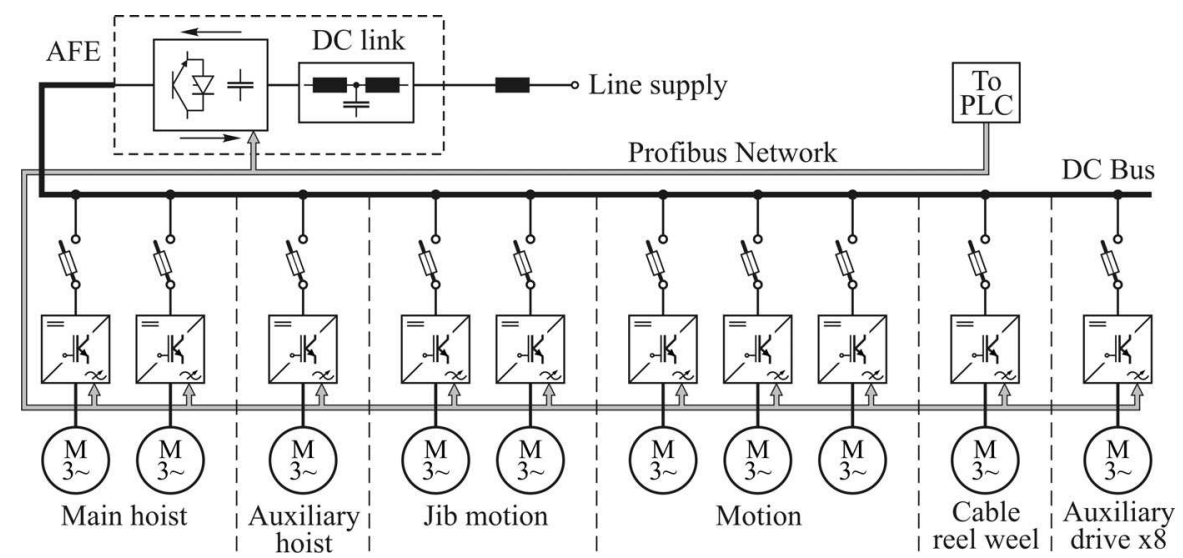

Fig. 14. Single line power circuit topology.

Fig.15a) shows a hoist movement with the $30 \%$ of full load and Fig.15b) for auxiliary hoist with an unloaded hook measured in similar conditions. In Fig.15a), curve 1 gives the actual speed signal (reference speed signal is given at 100\% from the crane driver joystick command). Curves 2, 3 and 4 show the torque, power and motor current, respectively. After an acceleration period (ending at $5 \mathrm{~s}$ ), a constant torque is delivered. This transition in torque level coincides with reaching the prescribed speed. At $17.5 \mathrm{~s}$, the speed reference signal is made zero (stop command). The driving torque becomes zero and the system decelerates due to gravity. After $20 \mathrm{~s}$, zero speed is reached, and the drive has to deliver the torque required for holding the load before closing the mechanical brake. After that the same the same measurements were performed during lowering. Due to high friction losses, torque was required to start the decent. After short initial period, only the dynamic friction is present, yielding a small driving torque. After the acceleration, the power flow is reversed and the drive lowers the load at a constant speed. From $43 \mathrm{~s}$ on, the system is braked with maximum torque, until standstill.

The same measurements were performed during lowering and hoist movement with the $30 \%$ of full load, Fig. 16a). The reference speed was 25, 50, 75 and $100 \%$ of rated speed. As on the Fig.15 actual speed, motor torque, power and current are shown. After that for jib-boom motion the same signal was record as shown on Fig.16b). In both figure regenerative periods during the lowering, at any reference speed, can be seen.

From the Fig.15 and Fog.16, can be seen periods when the energy recovery occurs at the point of load lowering. It is very important to point out that the AFE topology allows for fully regenerative operation, which is quite important for crane application. 

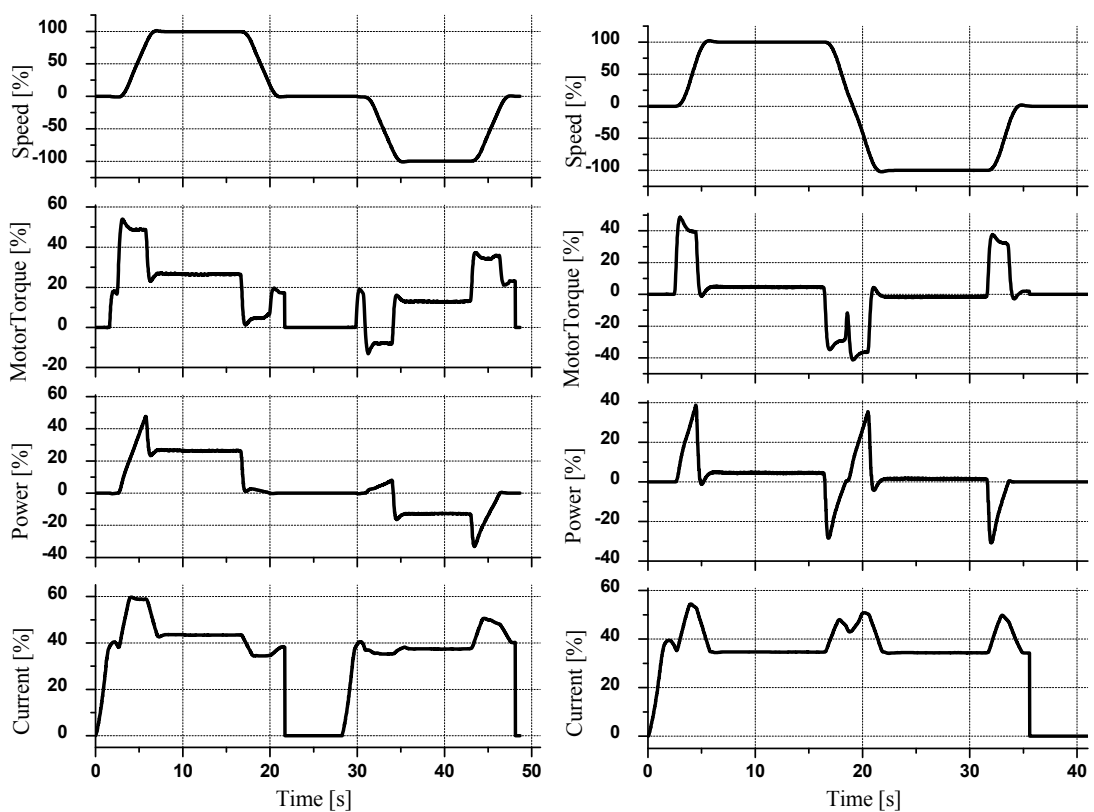

Fig. 15. Measured pattern of the a) hoist motion, b) auxiliary hoist.
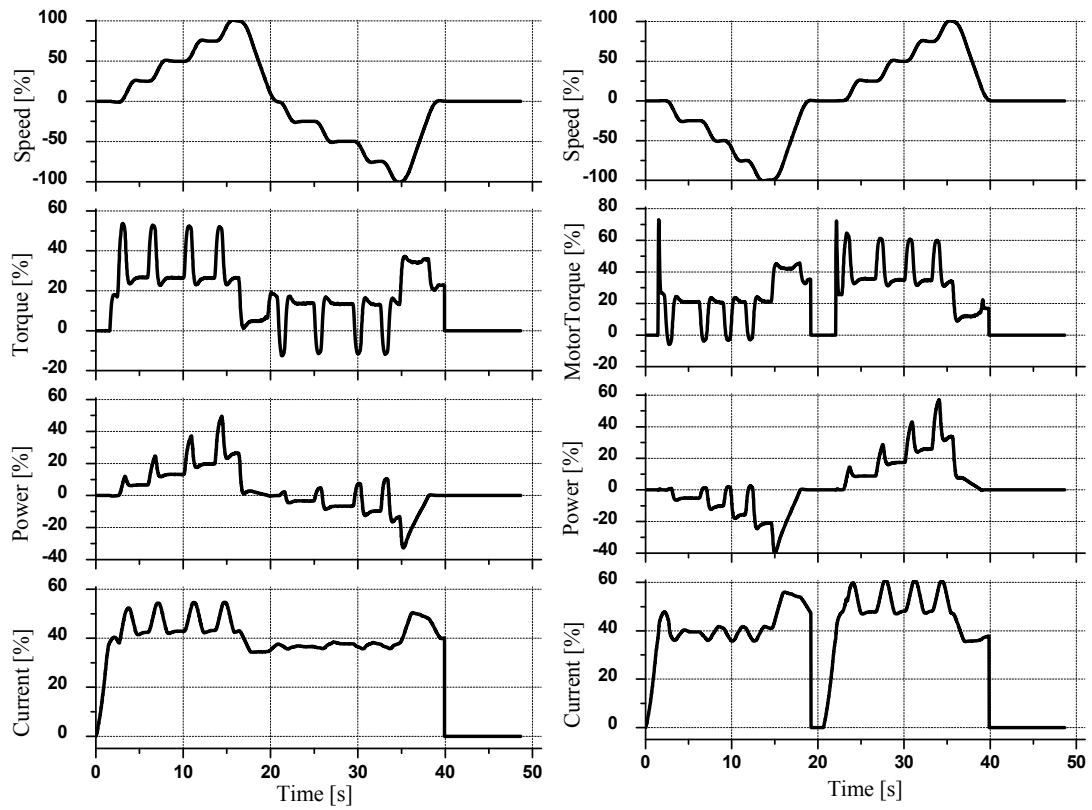

Fig. 16. Measured pattern at $25,50,75$ and $100 \%$ of rated speed a) hoist motion, b) jib motion. 
Different tests have been performed on the system to show some of the capabilities in the AFE inverter system. The measurements are done at steady-state operation. During experiments, the DC link voltage is boosted to $650 \mathrm{~V}$. The first test is rectifier system operation when the induction machine operates as motor during lifting of the load, Fig.17a), and second test is regenerative operation during lowering of the load, Fig.17.b). Both figures show the measured line currents, line voltages and DC voltage. It can be observed a high stationary performance both in motor and generator operation. The line current is nearly a sine wave with unity power factor while DC voltage is unchanged.
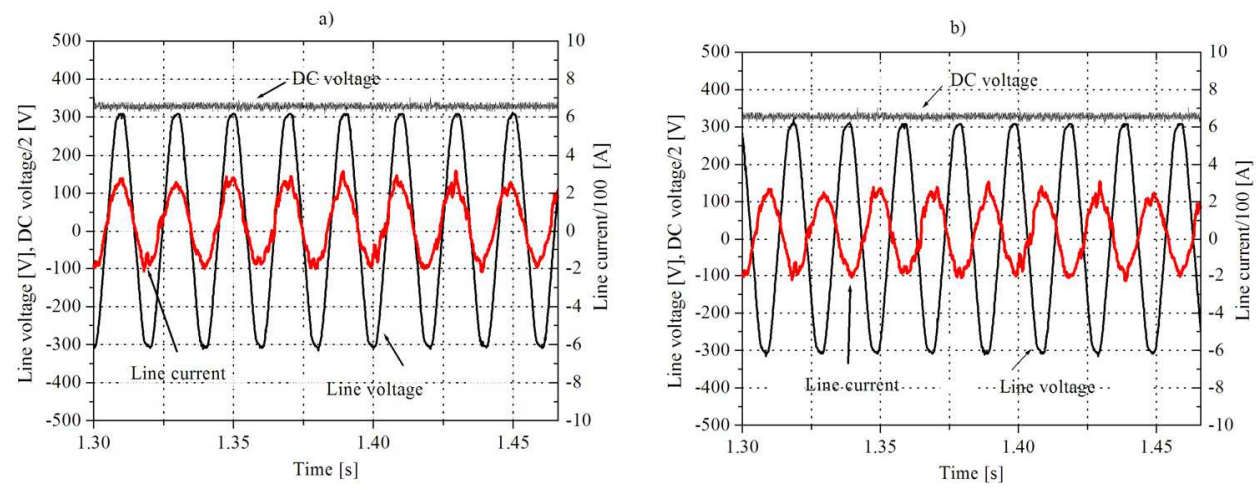

Fig. 17. Waveforms under steady-state operation: Line voltage, line current and dc link voltage a) motor operation, b) generator operation.

\section{Case study 2: Wide span gantry crane}

The experimental behavior analysis of some drives is considered on the example of crane with wide span, which in sugar factory serves for continuous transport of sugar beet from the reception position to the factory storage.

The crane with following details has been taken for experimentation with adjustable frequency drive:

- Handling capacity: $500 \mathrm{t} / \mathrm{h}$;

- Gantry span: $64.5 \mathrm{~m}$;

- $\quad$ Runway rail path: 300 m;

- Hoist height: $18 \mathrm{~m}$;

- Working conditions: outdoor.

Gantry crane for sugar beet storage is designed from the following functional parts:

1. Gantry drive $(16 \mathrm{~m} / \mathrm{min})$ with four induction motors of $5.5 \mathrm{~kW}$, two per leg.

2. System conveyor belts $(2 \mathrm{~m} / \mathrm{s})$ with "battered" $(30 \mathrm{~kW})$, horizontal $(30 \mathrm{~kW})$ and "butterfly" conveyor $(11 \mathrm{~kW})$.

3. Trolley drive $(12 \mathrm{~m} / \mathrm{min})$ with four motors of $1.1 \mathrm{~kW}$.

4. "Butterfly" hoist $(3 \mathrm{~kW})$.

5. Motor driven cable reel $(1.1 \mathrm{~kW})$.

6. Decentralized crane control system with appropriate PLC, Profibus communication between converters and other intelligent devices (encoders, operator panels etc.). 
In the Fig.18 gantry crane with indicated drives is shown. All motors are three phase fed by frequency converters.

Certainly, the most complicated is the gantry drive, from following reasons:

- that is multi motor drive which consists of two motors on each side,

- the span is wide,

- construction is lattice, therefore it is elastic,

- plant is located outdoor so the influence of the wind may be considerable,

- the length of runway rail path is $300 \mathrm{~m}$.

Basic requirements set in front of this drive are: equal load distribution between motors located on the same side, as well as skew elimination between fixed and free gantry leg.

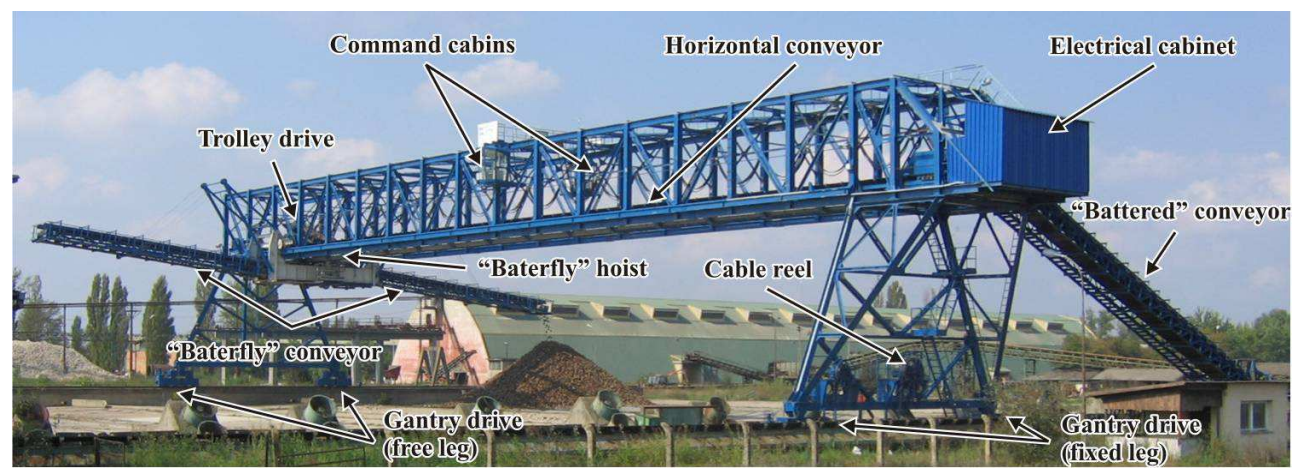

Fig. 18. Gantry crane with indicated drives.

\subsection{Load sharing}

Although the motors have the same power, there are few necessary reasons to do the load distribution: different wheel diameter, unequal adhesion, geometrical imperfection of the construction, slipping of the pinion wheel due to wet or frozen rails. Load distribution is resolved by using speed trim load sharing configuration, Fig.1c). Load distribution controller is realized by PLC.

In the Fig.19 the principle block scheme for load distribution between two rail coupled induction motors $\left(\mathrm{IM}_{1}\right.$ and $\left.\mathrm{IM}_{2}\right)$ fed by frequency converters (FC1 and FC2) is shown. Starting point at design of load sharing controller is that the less loaded motor should accelerate in order to take over the part of load from the more loaded motor. Information about the load can be obtained in different ways. The easiest one is by motor current. Modern converters used in drives, enable to obtain information about the motor torque in percentage in relation to rated torque.

As we can see in the Fig.19, the speed reference of only one motor $\left(n_{2}^{*}\right)$ is updated in relation to the main speed reference $\left(n^{*}=n_{1}^{*}\right)$. Reference correction $\Delta n^{*}$ is proportional to the 
difference of estimated electromagnetic torque $\left(\Delta T_{e}=T_{e 1}-\Delta T_{e 2}\right)$. Proportional gain of load sharing regulators is denoted as $K_{L S}$.

In order to ensure the stabile operation of the motors during the large external disturbances, especially at low speed when estimation of electromagnetic torque in speed sensorless drives looses on accuracy, it is necessary to limit the correction value $\Delta n^{*}$, as shown in Fig.19.

For the purpose of suggested algorithm verification the trolley load sharing is analyzed. Because of the short distance between left and right side the skew may be neglected. Trolley drive consists of four motors, two on each side ( $\mathrm{IM}_{1}-\mathrm{IM}_{2}$ on left and $\mathrm{IM}_{3}-\mathrm{IM}_{4}$ on right side). Frequency converters are set on speed sensorless vector control mode. Motors have the common reference speed. In the Fig.20a) motors torque without load distribution is shown. At reference speed, in steady state, we can see that even the motors have the same rated power, load torques are different. Estimated motor torque is not applied in control algorithm. Speed between left and right side is different because it depends of motor characteristics and load, as shown in Fig.20a).

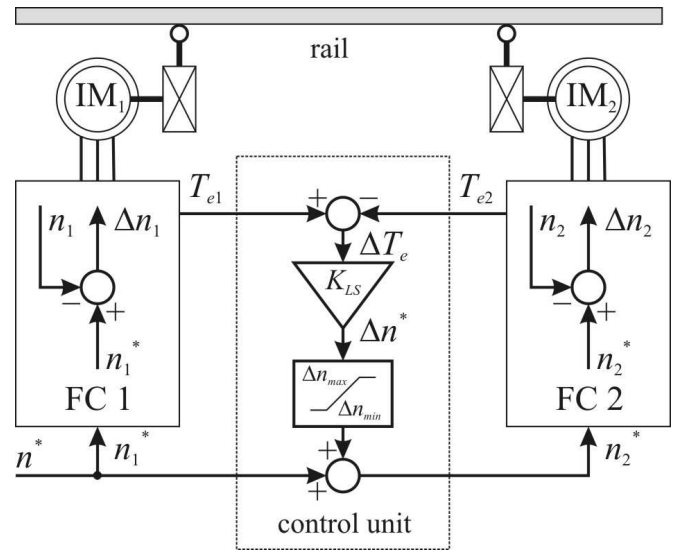

Fig. 19. The principle of load sharing based on estimated torque.

Effect of load sharing is shown in Fig.20b). The approximately equal motors torque on the same leg can be easily seen. Used system enables that speed of every motor is regulated, but also the load difference is controlled. In this way the load difference is being maintained on the desired accuracy.

Depending on the purpose of drives and needed accuracy of maintaining load distribution, load controller can be with only proportional effect, but also with proportional integrated effect. In our case only proportional controller with $K_{L S}=1$ p.u. is used. Output from the load controller is restricted on only several percentages of maxsimum speed reference (in our example $\Delta n_{\min -\max }=2 \%$ ). That is quite enough to provide necessary load regulation and not to "break" the drive speed regulation by too big effect on the speed reference. This solution can be applied for all kinds of multi motor drives on cranes. 

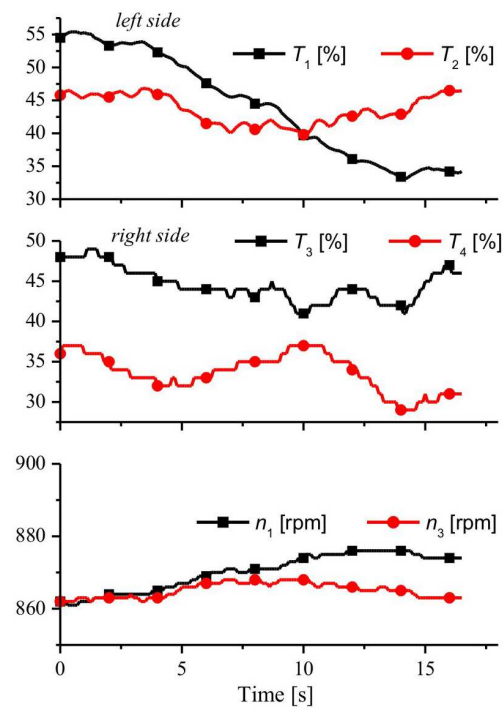

a)
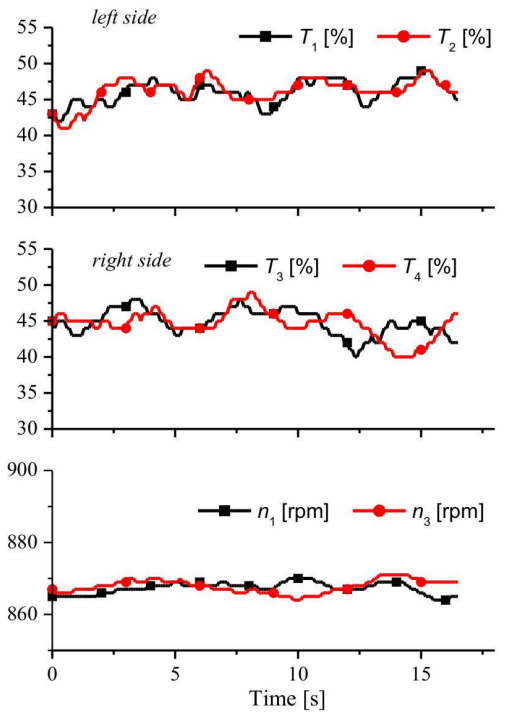

b)

Fig. 20. Motors torque and speed: a) without load sharing; b) with load sharing.

\subsection{Skew elimination}

On most rails mounted wide span gantry cranes skewing problem is associated with poor rail conditions, uneven wheel wear, wind influence, wheel slippage or unequal load conditions when the trolley is operating at one end of the crane bridge. The skewing of the crane can cause excessive wheel abrasion and stress, especially to the wheel flanges. It can also produce horizontal or lateral forces that can result in unusual stresses to the crane runway beams and building structure. This often results in differing diameters of drive wheels, which subsequently cause the crane to skew.

The crane construction consists of opposed pairs of end truck assemblies (left hand side is named as free leg and right hand side is named as fixed leg). These are movable along a track and a long transverse support member between the end truck assemblies. Each end truck assembly includes two sets of trolleys and an upper load bar laterally interconnects the two sets of trolleys.

The hardware for skew elimination consists of a PLC with Field-bus communication, two absolute multi-turn encoders, two proximity sensors and four frequency converters for motor supply of trolley drives, as shown in Fig.21). On each end truck, one of the converters is master and the other one is slave. The master-slave references distribution is modified according to the load sharing principle as shown in Fig.1c).

The main devices for skew tracking are two absolute encoders $\left(E_{1}\right.$ and $\left.E_{2}\right)$ installed on a special, non-tractive wheel (so called free wheel), in order to avoid slipping. Encoders measure the traveled distance, and absolute position is transferred to the anti-skew control subsystem in PLC, as shown in Fig.21). The fixed leg frequency converter $\left(\mathrm{FC}_{1}\right)$ is set as a 
master for gantry drive skew elimination algorithm; while in this case, the speed reference for the frequency converter on the free leg $\left(\mathrm{FC}_{2}\right)$ is modified with the anti-skew controller output.

The control scheme for skew elimination between the master and slave motor of gantry drive is shown in detail in Fig.22). As it can be seen, we propose a simple proportional (P) controller acting as an additional, outer correction loop, which supplies speed control loop. The speed reference of one motor $\left(n_{2}^{*}\right)$ is updated in relation to the main speed reference $\left(n^{*}=n_{1}^{*}\right)$ with reference correction value $\Delta n^{*}$. If the encoder position difference $\Delta E$ related to maximum allowed skew is known, the controller gain $K_{S C}$ can be calculated, (Mitrovic et al., 2010).

In order to ensure the stabile and safe operation of the motors during the large external disturbances and at low speed, when estimation of electromagnetic torque in speed sensorless drives looses on accuracy, it is necessary to limit the correction value $\Delta n^{*}$.

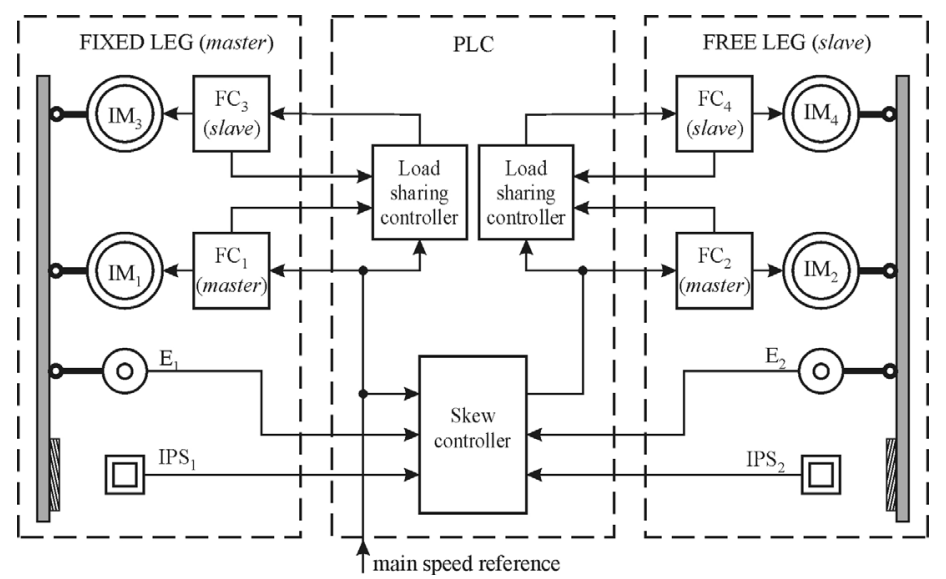

Fig. 21. Block scheme of gantry drive.

A reliable operation (even in terms of key components failure - for example encoders) requests an additional external disturbance compensator (EDC) which includes several pairs of position bars (or markers, M) and inductive proximity sensors (IPS). The EDC takes into account all external influences on the position difference of the two encoders: the free wheels diameter difference and an accidental wheel and encoder joint slipping.

The proximity sensors are fitted on the end truck holders, while the position bars are equidistantly mounted along the rails. During the crane movement, proximity sensors detect the moment when the fixed (or free) leg passes above the markers and so register the crane actual skew. Now when both legs are positioned on the markers, absolute encoders measure the trajectory difference, as shown in Fig.22). In fact, this difference is the real skew (s) of the crane, determined at each crossing over the markers. If the difference is greater than the length of the markers $\left(l_{m}\right)$ that means the crane skew is bigger than allowed. For this reason it is required that the length of markers matches the allowed skew of the crane. The distance between successive markers $\left(l_{m s}\right)$ depends on the length of marker and maximum expected liner speed difference between the legs. 


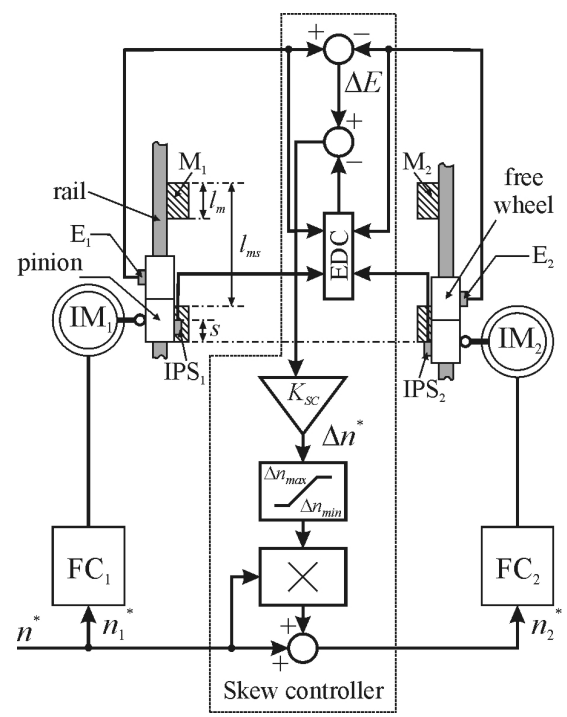

Fig. 22. The principle block diagram of skew controller.

The limited number of the necessary input data for the calculation and design of the skew controller allows quick adjustment of parameters and the choice of EDC components, and the proposed algorithm makes it suitable for industrial applications.

In the analyzed example, the loads of fixed and free legs are different, partly because of asymmetry of gantry, but mostly because of the trolley moving along the gantry. The calculated critical skew of gantry structure is $100 \mathrm{~cm}$, but during normal operation the maximum allowed skew is $50 \mathrm{~cm}$. A preview of gantry drive parameters, controller design and set-up values are taken from reference (Mitrovic et al., 2010).

At the beginning, we analyzed the behavior of gantry drives without a skew controller and the main results are shown in Fig.23a).

In this case, the load-sharing controllers for the fixed and free gantry leg are applied. Three working sections are noticeable: crane acceleration, steady state operation, and crane deceleration. The encoder measures the motor speed, while torque is estimated from the frequency converters. The measured data are collected in PLC SCADA system. The observed variables are master motor $\left(\mathrm{IM}_{1}\right)$ speed $n_{1}$, speed difference $n_{1}-n_{2}$ between the master motor $\left(\mathrm{IM}_{1}\right)$ on the fixed leg and the master motor $\left(\mathrm{IM}_{2}\right)$ on the free leg, torque differences between motors on the same leg $\left(\mathrm{IM}_{1}-\mathrm{IM}_{3}, \mathrm{IM}_{2}-\mathrm{IM}_{4}\right)$ and the value of actual skew (s). In this case, as the skew is not controlled, it can be seen the increase of the value. During the crane skew, motors $\left(\mathrm{IM}_{1}\right.$ and $\left.\mathrm{IM}_{3}\right)$ on the fixed leg are more loaded than the motors $\left(\mathrm{IM}_{2}\right.$ and $\mathrm{IM}_{4}$ ) on the free leg. In addition to that, the effects of the load-sharing controller can be noticed because the motors on the same leg share loads approximately, i.e. torque difference oscillates about zero value.

The next experiment was performed including the skew controller and under the similar operational regimes as in the previous case: acceleration, steady state operation and deceleration. The experimental results are shown in Fig.23b). During the crane 
acceleration/deceleration, due to different loads between the fixed and free leg temporarily skew can be observed. The skew controller action eliminates this start-up disturbance in a few seconds. Simultaneously, with the action of a skew regulator, load-sharing controllers provide motor loading in proportion to their rated power. At constant speed operation, the trolley moves between the fixed and free leg, which causes additional differences in loads, but the proposed controller successfully compensates for these disturbances. In the case of crane deceleration, it can be seen that the characteristic case of the free leg stopping is postponed in order to complete the elimination of skew and for the fine position adjustment.
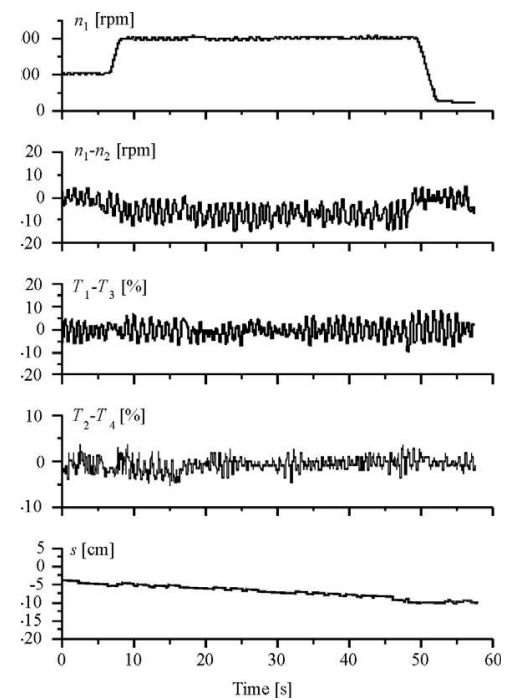

a)
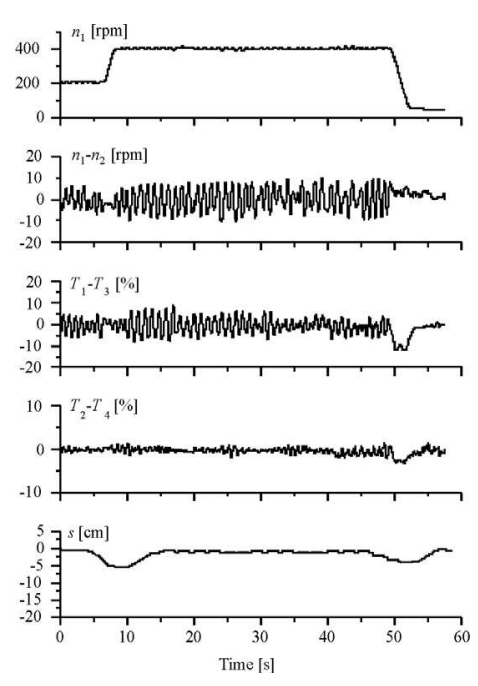

b)

Fig. 23. Behavior of gantry drives: a) without skew controller; b) with skew controller.

\section{Conclusion}

The application of squirrel cage induction motors supplied from the frequency converters (also known as adjustable speed drive) have become the standard solution for the modern crane drives. However, the standard configuration of the inverter can not be used for some drives primarily due to regenerative operation, which in some cases may be intermittent (long travel and cross travel) and continuous (lowering). The power and torque requirements in details are described and analyzed for such drives. From the aspect of the required power crane drives are often implemented as a multi motor. One of the important issue in this case is load distribution between the motor proportional to the motor power rating which can be resolved by applying the modern converters in one of the master-follower configuration.

This chapter describes the solutions that are commonly used in modern crane drives. In case that it is a casual recuperating the dynamic braking is used. If continious regeneretation occur active front end rectifier capable to returning energy into the supply network is used. The following two case studies are selected. Case study 1 is typical because the AFE is used which in addition of power recovery possibility also serves to supply all the drives on the 
common DC bus. Case study 2 deals with gantry cranes that have a large span. Solutions of two problems that occur in these types of cranes are shown as follows: load distribution between multiple motor and skew problem as a result of a large span.

\section{Acknowledgment}

This paper is supported by Project Grant III44004 (2011-2014) financed by Ministry of Education and Science, Republic of Serbia.

\section{References}

ABB, Technical guide No.8, Electrical Braking, 2011.

Backstrand, J.E. (1992). The Application of Adjustable Frequency Drives to Electric Overhead Cranes, Industry Applications Society Annual Meeting, 1992, Conf. Rec.1992 IEEE 4-9 Oct. 1992, vol.2, pp.1986 - 1991.

Belmans R., Bisschots F. \& Timmer R. (1993). Practical Design Considerations for Braking Problems in Overhead Crane Drives, Conf. Rec. IEEE-IAS, Vol.1, pp. 473-479.

Busschots F., Belmans R. \& Geysen W. (1991). Application of Field Oriented Control in Crane Drives, Proc. IEEE-IAS, Annual Meeting, Dearborn, Michigan, USA, September 28-October 4, 1991, pp. 347-353.

Hartani, K. \& Miloud, Y. (2010). Control Strategy for Three Phase Voltage Source PWM Rectifier Based on the Space Vector Modulation, Advances in Electrical and Computer Eng., Vol.10, Issue 3, pp. 61-65.

Jeftenic B., Bebic M. \& Statkic S. (2006). Controlled Multi-motor Drives, Intern. Symp. SPEEDAM 2006, Taormina (Sicily) - Italy, 23-26 May 2006 , pp. 1392-1398.

Jiuhe, W., Hongren, Y., Jinlong Z \& Huade, L. (2006). Study on Power Decoupling Control of Three Phase Voltage Source PWM Rectifiers, Power Electronics and Motion Control Conference, 2006.

Mitrovic N., Petronijevic M., Kostic V. \& Bankovic B. (2011). Active Front End Converter in Common DC Bus Multidrive Application, XLVI Proc. of Inter. Conf. ICEST 2011, Serbia, Nis, Vol.3, pp. 989-992, 2011.

Mitrovic, N., Kostic, V., Petronijevic, M. \& Jeftenić, B. (2010). Practical Implementation of Load Sharing and Anti Skew Controllers for Wide Span Gantry Crane Drives“, JME, Vol. 56, no. 3, pp. 207-216, 2010.

Odavic M., Jakopovic Z. \& Kolonic F. (2005). Sinusoidal Active Front End under the Condition of Supply Distortion, AUTOMATIKA 46(2005), 3-4, pp.135-141, 2005.

Paul, A. K., Banerje, I., Snatra, B.K. \& Neogi, N. (2008). Application of AC Motors and Drives in Steel Industries, XV Natinal Power System Conference, Bombay, Dec.2008, pp.159163.

Petronijevic M., Veselic B., Mitrovic N., Kostic V. \& Jeftenic, B. (2011). Comparative Study of Unsymmetrical Voltage Sag Effects on Adjustable Speed Induction Motor Drives, Electric Power Applications, IET , vol.5, no.5, pp.432-442, May 2011

Rashid H., Power Electronics Handbook, Academic Press, San Diego, 2001.

Rockwell Automation (2000), Load Sharing for the 1336 PLUS II AC Drive, Publication number 1336E-WP001A-EN-P, June 2000.

Slutej, A., Kolonic, F. \& Jakopovic, Z. (1999). The New Crane Motion Control Concept with Integrated Drive Controller for Engineered Crane Application, ISIE'99, Proc.of the IEEE International Symposium, Volume 3, 1999, pp.1458 - 1461. 


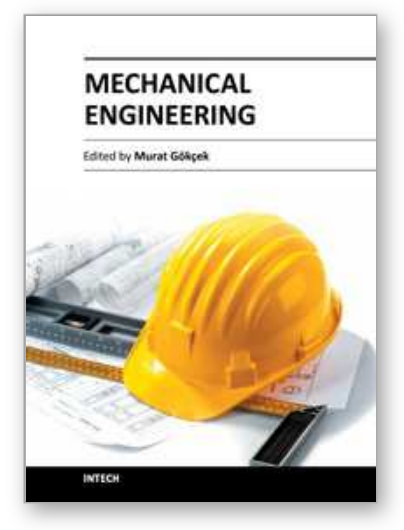

\author{
Mechanical Engineering \\ Edited by Dr. Murat Gokcek
}

ISBN 978-953-51-0505-3

Hard cover, 670 pages

Publisher InTech

Published online 11, April, 2012

Published in print edition April, 2012

The book substantially offers the latest progresses about the important topics of the "Mechanical Engineering" to readers. It includes twenty-eight excellent studies prepared using state-of-art methodologies by professional researchers from different countries. The sections in the book comprise of the following titles: power transmission system, manufacturing processes and system analysis, thermo-fluid systems, simulations and computer applications, and new approaches in mechanical engineering education and organization systems.

\title{
How to reference
}

In order to correctly reference this scholarly work, feel free to copy and paste the following:

Nebojsa Mitrovic, Milutin Petronijevic, Vojkan Kostic and Borislav Jeftenic (2012). Electrical Drives for Crane Application, Mechanical Engineering, Dr. Murat Gokcek (Ed.), ISBN: 978-953-51-0505-3, InTech, Available from: http://www.intechopen.com/books/mechanical-engineering/electrical-drives-for-crane-application

\section{INTECH}

open science | open minds

\author{
InTech Europe \\ University Campus STeP Ri \\ Slavka Krautzeka 83/A \\ 51000 Rijeka, Croatia \\ Phone: +385 (51) 770447 \\ Fax: +385 (51) 686166 \\ www.intechopen.com
}

\author{
InTech China \\ Unit 405, Office Block, Hotel Equatorial Shanghai \\ No.65, Yan An Road (West), Shanghai, 200040, China \\ 中国上海市延安西路65号上海国际贵都大饭店办公楼405单元 \\ Phone: +86-21-62489820 \\ Fax: +86-21-62489821
}


(C) 2012 The Author(s). Licensee IntechOpen. This is an open access article distributed under the terms of the Creative Commons Attribution 3.0 License, which permits unrestricted use, distribution, and reproduction in any medium, provided the original work is properly cited. 